\title{
MRI activity in MS and completed pregnancy
}

\section{Data from a tertiary academic center}

Maria Houtchens, MD, MSc, Riley Bove, MD, MSc, Brian Healy, PhD, Stepan Houtchens, BS,

Tamara Bockow Kaplan, MD, Tatenda Mahlanza, MSc, Tanuja Chitnis, MD, and Rohit Bakshi, MD

Neurol Neuroimmunol Neuroinflamm 2020;7:e890. doi:10.1212/NXI.0000000000000890

\section{Abstract}

\section{Objective}

To evaluate postpartum MRI activity in patients with MS and a completed pregnancy and to compare these results to an age-matched untreated nonpregnant MS cohort.

\section{Methods}

Patient with MS from a tertiary care MS center between 2006 and 2015, with prepartum and postpartum neurologic follow-ups and MRI scans were analyzed. Clinical activity and inflammatory brain MRI activity (new T2-hyperintense or gadolinium-enhancing [Gd+] lesions) were assessed peripartum. The results were compared with untreated reproductive-age patients with MS from the placebo arm of the clinical trials.

\section{Results}

A total of 123 pregnancies in 123 women (median Expanded Disability Status Scale 1.0) were analyzed. Approximately $7.2 \%$ relapsed during pregnancy and $48.7 \%$ relapsed postpartum. Of pregnancies with prepartum and postpartum gadolinium $(\mathrm{Gd})$-enhanced MRI $(\mathrm{n}=112), 8 \%$ had Gd+ lesions prepartum and 33\% had new Gd+ lesions postpartum. Overall, 54.4\% had either new T2 or Gd+ lesions postpartum. Seventy-nine percent of subjects with postpartum relapse had new MRI activity compared with $37.1 \%$ without relapse $(p<0.001)$. Twenty-five percent had both clinical and radiographic activity and only $24.9 \%$ maintained no evidence of disease activity status postpartum. There was no association between postpartum MRI activity and disease-modifying treatments (DMTs) $(p>0.5)$. MRI and clinical outcomes were also assessed for 126 nonpregnant untreated female patients with MS. Comparing pregnancy and no pregnancy groups, there was no difference in MRI activity at follow-up.

\section{Conclusions}

There was a high level of inflammatory radiographic disease activity which was related to relapses in postpartum patients with MS. Further studies are needed to determine whether hormonal fluctuations vs extended time off DMTs may be the underlying cause of our observations.

\author{
Correspondence \\ Dr. M. Houtchens \\ mhoutchens@bwh.harvard.edu
}




\section{Glossary}

CIS = clinically isolated syndrome; DMT $=$ disease-modifying therapy; EDSS $=$ Expanded Disability Status Scale; Gd = gadolinium; IFN = interferon; IL = interleukin; NEDA = no evidence of disease activity; NPC = no pregnancies cohort; $\mathbf{P C}=$ pregnancies cohort; RIS $=$ radiologically isolated syndrome; Th2 $=$ T helper 2.

MS affects 3 times more women than men, typically during the childbearing years. ${ }^{1,2}$ Reciprocal interactions between sex hormones and immune function may alter MS risk and course. $^{3,4}$ Reproduction is an important consideration for women with MS, and over the past 20 years, pregnancy rates in patients with MS have been increasing. ${ }^{5}$ Clinical disease activity is reduced in pregnancy, likely because of the immunotolerant state of pregnancy. ${ }^{4}$ In the postpartum period, the clinical attack rate increases up to 3 -fold, with up to one-third of women experiencing relapses. ${ }^{6}$ In women prospectively observed after the diagnosis of radiologically isolated syndrome (RIS), pregnancy was associated with a significantly shorter time to clinically definite MS. ${ }^{7}$ A tendency for rebound activity after discontinuation of certain highly efficacious disease-modifying therapies (DMTs) (e.g., fingolimod and natalizumab) has contributed to an increased relapse rate during pregnancy in some women., 8

Neuroimaging has the advantage of detecting acute inflammation and distinguishing between true MS-related activity and other peripartum causes of neurologic changes. ${ }^{10,11}$ Increased inflammatory activity after pregnancy on MRI has been reported in a small study of 28 Finnish women with MS and in women who became pregnant in the RIS cohort. ${ }^{712}$ In addition, failed assisted reproductive treatments can be followed by increased MS clinical and MRI activity, possibly implicating abrupt hormonal changes and loss of immunotolerance in promoting inflammation. ${ }^{13}$

To date, there are no large studies characterizing MRI-defined disease activity in the postpartum period. Our objectives were to describe the effects of completed pregnancy on MRI MS activity in a single academic center, to correlate clinical and MRI findings in the postpartum period, and to compare these results to a cohort of nonpregnant, untreated women with MS.

\section{Methods}

\section{Sample selection}

\section{Cohort 1: Pregnancies}

Medical records were reviewed to identify all reproductive-age adult women (18-45) with a diagnosis of MS by the 2005 McDonald criteria ${ }^{14}$ and a completed pregnancy who received care at Partners Multiple Sclerosis Center between January 1, 2006, and December 31, 2015. Our standard protocol for managing women with MS includes a baseline clinical and MRI examination before conception attempts and clinical and MRI follow-up within the first 6-12 months postpartum. The 10-year study period was selected to assure MRI platform and scan acquisition consistency. Participants were included if they became pregnant and had a live birth after MS diagnosis, had a clinical evaluation by their neurologist, and MRI scans within 12 months of pregnancy and postpartum. Of the 257 pregnancies in 255 patients with MS, 132 (51\%) were excluded because of pregnancy loss or termination or because of multiple missing data points. A total of 123 participants with 125 pregnancies met the study inclusion criteria for the pregnancies cohort (PC) (table 1). Two participants had 2 pregnancies each, separated by $\sim 2$ years. To avoid confounding outcomes with potential effects of previous pregnancies, only the first pregnancies (123) were considered for analysis. None of the subjects received DMT during pregnancy.

\section{Cohort 2: No pregnancies}

To isolate the effect of pregnancy vs untreated status on MRI activity in the postpartum period in cohort 1 and to avoid the potential bias toward "benign MS" inherent to patients not receiving DMTs in the clinical setting, we identified a second cohort of age-matched nonpregnant women with MS from the placebo arms of prospective, double-blind clinical trials. The baseline characteristics of this no pregnancies cohort (NPC) are shown in table 1. The ALLEGRO and BRAVO phase III trial data for laquinimod were provided by Teva Neuroscience. ${ }^{15,16}$ Enrollment criteria for both trials included age $18-55$ years, a diagnosis of relapsing-remitting MS by the 2005 McDonald Criteria, a score of no more than 5.5 on the Expanded Disability Status Scale (EDSS), and a disease duration of at least 6 months ${ }^{14,17}$ Patients were eligible for the trials if they were on no DMTs and if they satisfied strict clinical and MRI activity trial entry criteria. ${ }^{15,16}$

All participants underwent 12 scheduled assessments at the study sites during the double-blind phase of the study. Clinical scores were recorded every 3 months, and brain MRI scans were obtained annually. None of the participants became pregnant during the trial. The NPC female participants for our study were selected from this data set based on their untreated (placebo) status on unblinding, age 18-45 years, and the availability of both baseline and follow-up MRI scans.

\section{Data collection}

\section{Cohort 1: PC}

MS clinical history was extracted from medical records, including disease duration and MS type at conception, EDSS 
Table 1 Demographic/clinical characteristics of the 2 cohorts

\begin{tabular}{|c|c|c|c|}
\hline & Cohort 1: $\mathrm{PC}(\mathrm{N}=123)$ & Cohort 2: NPC $(\mathrm{N}=125)$ & $p$ Value \\
\hline Age, $y$, mean $\pm S D(\min , \max )$ & $32.8 \pm 5.0(18,44)$ & $32.2 \pm 7.2(18,44)$ & 0.46 \\
\hline Disease duration, $y$, mean $\pm S D(\min , \max )$ & $7.7 \pm 5.3(0,27)$ & $3.4 \pm 4.6(0.1,22)$ & $<0.001$ \\
\hline Baseline EDSS, median (IQR; range) & Prepartum visit: $1(0-2 ; 0-6.5)$ & $\begin{array}{l}\text { Clinical trial enrollment visit: } 1.5 \\
(1-1.5 ; 0-1.5)\end{array}$ & $0.07^{a}$ \\
\hline End of study period EDSS, median (IQR; range) & Postpartum visit: $1.5(1-2 ; 0-8)$ & 24 mo trial data point: $1.5(1-1.5 ; 0-6)$ & $0.92^{\mathrm{a}}$ \\
\hline \multicolumn{4}{|l|}{ Disease type, n (\%) } \\
\hline RRMS & $111(90.2)$ & $125(100)$ & \\
\hline CIS & $9(7.3)$ & & \\
\hline SPMS & $3(2.4)$ & & \\
\hline \multicolumn{4}{|l|}{ MRI intervals, $d$, mean $\pm S D(\min , \max )$} \\
\hline Interval between baseline MRI (1) and pregnancy & $162.3 \pm 125.4(3,578) ; N=117$ & N/A & \\
\hline Interval between pregnancy and postpartum MRI (2) & $107.6 \pm 96.7(3,513) ; N=123$ & N/A & \\
\hline Interval between MRI 1 and MRI 2 & $522.0 \pm 163.4(189,1,088) ; N=116$ & $730 \pm 18.8(550,762) ; N=113$ & $<0.001$ \\
\hline \multicolumn{4}{|c|}{$\begin{array}{l}\text { Abbreviations: CIS = clinically isolated syndrome; EDSS = Expanded Disability Status Scale; IQR = interquartile range; max = maximum; min = minimum; } N= \\
\text { number of subjects; N/A = not applicable; NPC = no pregnancies cohort; PC = pregnancies cohort; RR = relapsing-remitting MS; SPMS = secondary progressive } \\
\text { MS. } \\
\text { PC had a longer disease duration and shorter MRI interval than NPC. See table } 3 \text { and the figure for a comparison of baseline Gd status between groups. MRI/ } \\
\text { pregnancy time intervals were calculated for subjects with available data points. In NPC, the MRI } 2 \text { data point was available for } 113 \text { subjects because of } 12 \\
\text { subjects withdrawing from clinical trials. } \\
\text { a Wilcoxon rank-sum test was used for the comparison of EDSS values (2-sample } t \text { tests used for other comparisons). }\end{array}$} \\
\hline
\end{tabular}

score at each visit, DMT use before and after pregnancy, and the number of clinical relapses (in the year before pregnancy, during pregnancy, and in the 12 months after delivery). We also collected data on treatment with monthly IV steroids (given in lieu of DMT postpartum) and maternal breastfeeding status in the 12 months postpartum.

There are many factors that contribute to a woman's decision to breastfeed or resume DMT postpartum. During our study period, breastfeeding women were strongly advised to not take DMTs. We confirmed that none of the breastfeeding women were on DMT at the time of postpartum MRI. We also confirmed specific DMT exposures for nonbreastfeeding subjects. Breastfeeding status was assumed to be nonexclusive unless specifically noted in the medical records. We did not have precise data on the timing of discontinuing DMTs before conception or restarting DMTs in relationship to breastfeeding discontinuation.

Reports and images of the brain and cervical and thoracic spine MRI scans were reviewed. All but 2 neuroimaging scans were performed at the Brigham and Women's Hospital and included assessment for the presence of new T2-weighted hyperintense lesions relative to previous MRI and gadolinium-enhancing $(\mathrm{Gd}+)$ lesions when contrast was administered. The study PI (M.H.) reviewed all images when reports indicated new $\mathrm{T} 2$ or $\mathrm{Gd}+$ lesions for confirmation of findings. Lesion counts were not formally performed, but the results were categorized based on the number of new T2 of $\mathrm{Gd}+$ lesions indicated in the neuroradiology report (none, 1 , 2 , or greater than 2 ; figure).

\section{Clinical relapses}

A clinical relapse was prospectively recorded by the treating neurologist using a standardized definition of acute or subacute neurologic symptoms, with clinical evidence of at least 1 CNS lesion, lasting more than 24 hours and in the absence of fever or other signs of infection. ${ }^{18} \mathrm{~A}$ relapse was defined as occurring after a stable neurologic state for at least 30 days. Participants could have received steroid therapy for moderate to severe relapses (typically, IV methylprednisolone: $1 \mathrm{~g} / \mathrm{d}$ for 3-5 consecutive days), but steroid treatment was not required for relapse confirmation.

\section{Disability evaluation}

The EDSS score ${ }^{17}$ was documented at the prepartum visit, at the postpartum visit, and during any neurologic relapse in pregnancy. Confirmed disability progression was defined as an increase in the EDSS score of at least 1.0 point from baseline if the baseline score was between 0 and 5.0 or an increase of at least 0.5 points if the baseline score was 5.5 or more, with the increase sustained for at least 3 months. Clinical outcomes also included the proportion of participants with a documented postpartum relapse and the proportion of 
Figure Gd MRI activity: Baseline vs follow-up

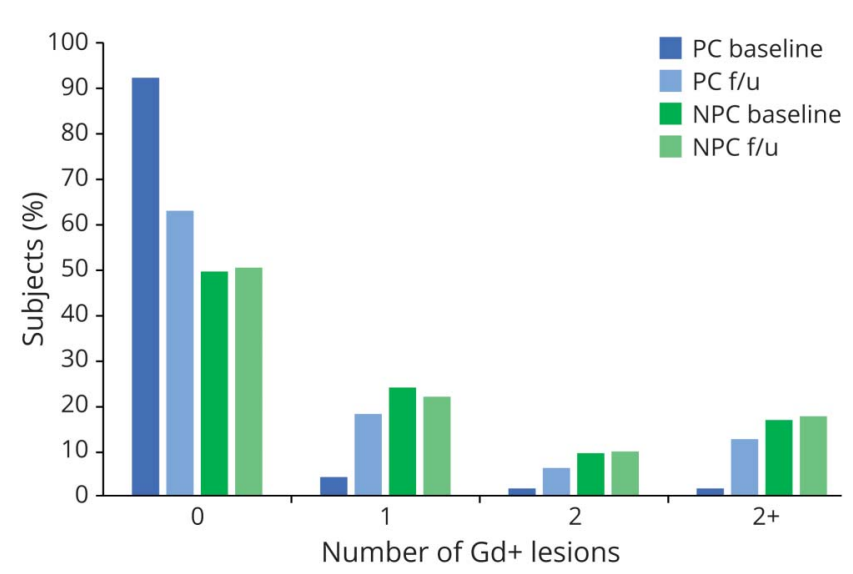

Comparison of all subjects from the PC and the NPC regarding the MRI Gd number of lesions at baseline and $f / u$. The number of $\mathrm{Gd}$ lesions per subject is binned as none, 1, 2, or greater than $2(2+)$. Although the PC started the study as less active than the NPC, at f/u, the PC showed marked increased activity, whereas the NPC remained active to a similar extent to baseline. After adjustment for disease duration and MRI interval, there was no group difference in the follow-up Gd+ lesion counts. See table 3 for the number of subjects and more details. $\mathrm{f} / \mathrm{u}=$ follow-up; $\mathrm{Gd}=$ gadolinium; $\mathrm{NPC}=$ no pregnancies cohort; PC = pregnancies cohort.

participants with a documented EDSS change at the postpartum visit.

\section{MRI acquisition}

During the analysis time frame, clinical brain and spinal cord MRI scans were routinely performed at $1.5 \mathrm{~T}$ including brain axial dual fast spin-echo, axial fluid-attenuated inversion recovery, and axial $\mathrm{T} 1$ spin-echo both before and 5 minutes after injection of $0.1 \mathrm{mmol} / \mathrm{kg}$ of Gd. Spinal cord MRI included $\mathrm{T} 2$-weighted sagittal and axial fast spin-echo images, and T1weighted sagittal and axial post-Gd images. There were a few cases for whom Gd was not administered (see below). Breastfeeding patients who received Gd were instructed to subsequently discard breastmilk for 24 hours as per the standard of clinical care.

\section{MRI outcomes}

MRI outcomes included new T2 or new Gd+ lesions in the brain or spinal cord in the postpartum period. An active scan was defined by the presence of either new T2 or new Gd+ lesions.

Prepartum MRI data were available for 115 subjects (93.4\%), and 114 scans (99.1\%) were performed with $\mathrm{Gd}$; postpartum MRI data were available for 122 subjects (99.2\%), 120 of which $(98.3 \%)$ were performed with Gd; 2 scans performed without contrast were performed at the outside imaging facilities. For these, the results were obtained from clinical neurology follow-up notes. Both prepartum and postpartum MRI studies were available for 113 of 123 participants $(91.8 \%)$.

\section{Cohort 2: NPC}

MS clinical history was extracted from the ALLEGRO and BRAVO trial data provided by Teva Neuroscience. ${ }^{15,16,19}$

\section{Clinical data}

The same definition of relapse was used for cohort 2 , as for cohort 1 (see above). The same definition for confirmed EDSS disability progression was used for the NPC as for PC (see above). Clinical outcomes included the proportion of participants with a documented relapse and/or a change in EDSS at the 24-month study point.

\section{MRI measures and outcomes}

Imaging protocols for ALLEGRO and BRAVO clinical trials used brain imaging only on scanners with a minimum field strength of $1.5 \mathrm{~T}$. Axial fast/turbo spin-echo proton density and $\mathrm{T} 2$-weighted images were obtained in addition to axial T1-weighted images both before and 5 minutes after injection of $0.1 \mathrm{mmol} / \mathrm{kg}$ of $\mathrm{Gd}$. Imaging outcomes included the number of new T2 lesions and new $\mathrm{Gd}+\mathrm{le}$ sions at month 24 . We selected the MRI at 2 years (730 days) as the closest comparison time point to the PC (table 1).

\section{Standard protocol approvals, registrations, and patient consents}

This work was approved by the institutional review board at Brigham and Women's Hospital.

\section{Data availability}

Anonymized data will be shared upon request with any qualified investigator.

\section{Statistical analysis}

For the primary analysis involving Cohort 1, PC, we detailed intrapartum and postpartum disease activity by estimating the proportion of subjects who had different types of disease activity and calculating an exact binomial confidence interval for the proportion. The associations between postpartum and prepartum radiologic disease activity (new T2 or Gd+ lesions) was assessed using a $\chi^{2}$ test and logistic regression to adjust for age and disease duration. The association between breastfeeding, treatment changes, steroid use, and disease activity postpartum were assessed using a $\chi^{2}$ test. To assess if the timing of the postpartum MRI was associated with the presence of a new T2 lesion postpartum, the duration of time until the MRI was compared between subjects with and without radiologic disease activity using a 2-sample $t$ test. To ensure that our conclusions were robust to the normality assumption of the 2-sample $t$ test, we also compared the groups using the Wilcoxon rank-sum test and the results were similar (data not shown). The association between EDSS prepartum and EDSS postpartum and the presence of a new T2 lesion postpartum was assessed using a Wilcoxon ranksum test. In group comparisons of on-study MRI activity, we 
used unadjusted logistic regression models and adjusted logistic regression models accounting for disease duration and time between scans. Alpha was set at 0.05 , and all tests were 2-sided. All analyses were performed with $\mathrm{R}$ version 3.6.3 (r-project.org).

\section{Results}

\section{Cohort 1: PC}

Baseline preconception demographic, clinical characteristics, and Gd MRI characteristics are reported in table 1 and the figure. All participants discontinued DMTs before conception. Information about postpartum DMT was available for 120 participants (table 2). Sixty-three participants (52.5\%) changed their treatment status in the postpartum period. Changes included DMT escalation to higher efficacy DMT $(\mathrm{n}=23)$ and substitutions within the general DMT category such as within injectable DMTs $(\mathrm{n}=10)$, first time DMT initiation $(n=21)$, or failure to resume any DMT $(n=9)$. None of the participants de-escalated to less efficacious treatment after pregnancy.

Table 2 DMTs prepartum and postpartum in the pregnancies cohort at the time of MRI acquisition

\begin{tabular}{|c|c|c|}
\hline $\begin{array}{l}\text { DMT (within } 12 \text { mo pre/ } \\
\text { postpartum) }\end{array}$ & $\begin{array}{l}\text { Prepartum DMT } \\
(\mathrm{N}=123)\end{array}$ & $\begin{array}{l}\text { Postpartum DMT } \\
(\mathrm{N}=120)\end{array}$ \\
\hline None, $n$ (\%) & $36(29.3)$ & $36(30)$ \\
\hline Any, n (\%) & $87(70.7)$ & $84(70)$ \\
\hline Injectables, n (\%) & $65(52.8)$ & $41(34.1)$ \\
\hline Beta interferons & 37 & 20 \\
\hline Glatiramer acetate & 28 & 21 \\
\hline Infusions, n (\%) & $15(12.2)$ & $22(18.3)$ \\
\hline Natalizumab & 12 & 15 \\
\hline Daclizumab & 2 & 0 \\
\hline Cyclophosphamide & 1 & 3 \\
\hline Rituximab & 0 & 4 \\
\hline Orals, n (\%) & $7(5.7)$ & $21(17.5)$ \\
\hline Fingolimod & 6 & 12 \\
\hline Dimethyl fumarate & 0 & 9 \\
\hline Methotrexate & 1 & 0 \\
\hline $\begin{array}{l}\text { Methylprednisolone, } 1 \mathrm{~g} \\
\text { monthly, } \mathrm{n}(\%)\end{array}$ & $12(9.8)$ & 19 \\
\hline With DMT & 7 & 3 \\
\hline Without DMT & 5 & 16 \\
\hline
\end{tabular}

Abbreviation: DMT = disease-modifying therapy.

There was an increase in the utilization of oral and infusion DMTs in the postpartum period. Over $50 \%$ of participants changed their treatment status (started a new DMT or escalated to more efficacious DMT) postpartum.

\section{Clinical and MRI postpartum outcomes}

Ten of 123 participants $(8.1 \%)$ had a documented clinical relapse during pregnancy (all patients received intrapartum steroids for relapse). Two participants were taking fingolimod, and one was on natalizumab prepartum. The remaining subjects with intrapartum relapses received glatiramer acetate $(\mathrm{n}=3)$, interferon (IFN) $(\mathrm{n}=2)$, or were untreated $(\mathrm{n}=2)$ before pregnancy. All subjects discontinued treatment before pregnancy in accordance with product label recommendations. Information on clinical postpartum relapses was available for 121 patients. Fifty-nine pregnancies (48.8\%) were followed by a clinical relapse within 6 months postpartum (95\% CI 39.6\%-58.0\%).

The MRI results in the PC group are detailed in table 3 and figure. On MRI, these subjects were largely inactive at baseline with $\sim 92 \%$ showing no $\mathrm{Gd}+$ lesions. However, at the followup postpartum scans, $\sim 54 \%$ developed MRI-defined disease activity (either a new $\mathrm{T} 2$ or $\mathrm{Gd}+$ lesion) (95\% CI $44.8 \%-63.3 \%)$, and 41 of 120 (34.2\%) demonstrated Gd+ lesions (95\% CI $25.8 \%-43.4 \%$ ).

Furthermore, when specifically considering subjects in the PC group who were $\mathrm{Gd}-$ at baseline, $32 \%$ developed $\mathrm{Gd}+$ lesions at the follow-up. Regarding new T2 lesions, these were noted in $\sim 44 \%$ of subjects with PC at the follow-up; in addition, this same rate of new T2 lesions was noted in subjects with PC who were $\mathrm{Gd}-$ at baseline.

Prepartum MRI activity was not associated with an increase in the likelihood of postpartum activity. Seventeen of 32 subjects with prepartum activity had postpartum activity compared with 44 of 80 subjects without prepartum activity had postpartum activity $\left(\chi^{2}\right.$ test $\left.p=0.86\right)$. After adjusting for age and disease duration, the association remained weak (OR 0.88; 95\% CI 0.38-2.03; $p=0.76$ ). When the association between a relapse and any MRI change was assessed, $71.9 \%$ (41 of 57) of subjects with a relapse had MRI activity compared with $37.1 \%$ (23 of 62) of subjects without a relapse $\left(p<0.001, \chi^{2}\right.$ test). Furthermore, only $24.9 \%$ of patients satisfied disease-free status or no evidence of disease activity (NEDA) criteria at the time of postpartum evaluation. ${ }^{20-22}$

\section{Pregnancies cohort sensitivity analyses: Association between clinical factors and risk of inflammatory activity postpartum}

We assessed whether the variability in duration between delivery and the postpartum MRI was associated with the risk of developing new T2 lesions between MRI scans 1 and 2. The 54 subjects with a new $\mathrm{T} 2$ lesion at the follow-up scan had 554 (175) days between scans compared with the 62 subjects without a new T2 lesion who had a time between scans of 494 (149) days (estimated mean difference $=59$; $95 \%$ CI -1.2 to $119.3 ; p=0.055$ ). There was no association between EDSS recorded at prepregnancy baseline or postpartum visits and new MRI activity postpartum $(p>0.05$; Wilcoxon rank-sum test). 
Table 3 MRI activity in the PC vs NPC

\begin{tabular}{|c|c|c|c|c|c|c|c|}
\hline & \multirow[b]{2}{*}{$\mathbf{N}$} & \multicolumn{4}{|c|}{ No. (\%) of participants with lesions } & \multirow[b]{2}{*}{ Unadjusted OR: PC vs NPC } & \multirow[b]{2}{*}{ Adjusted OR: PC vs NPC } \\
\hline & & 0 & 1 & 2 & $2+$ & & \\
\hline \multicolumn{8}{|l|}{ MRI time point 1} \\
\hline \multicolumn{8}{|l|}{ Gd+ lesions } \\
\hline PC & 114 & $105(92.1)$ & $5(4.4)$ & $2(1.8)$ & $2(1.8)$ & $0.08(0.04-0.18) ; p<0.001$ & $0.08(0.03-0.18) ; p<0.001$ \\
\hline NPC & 125 & $62(49.6)$ & $30(24)$ & $12(9.6)$ & $21(16.8)$ & & \\
\hline \multicolumn{8}{|l|}{ MRI time point 2} \\
\hline \multicolumn{8}{|l|}{ Gd+ lesions } \\
\hline PC (all) & 120 & $79(62.7)$ & $20(18.1)$ & $7(6.3)$ & $14(12.7)$ & $0.53(0.31-0.90) ; p=0.018$ & $0.60(0.28-1.28) ; p=0.19$ \\
\hline NPC (all) & 113 & $57(50.4)$ & $25(22)$ & $11(9.7)$ & $20(17.6)$ & & \\
\hline PC (Gd- at baseline) & 103 & 70 & 17 & 5 & 11 & $0.92(0.46-1.83) ; p=0.81$ & $0.999(0.40-2.49) ; p=0.99$ \\
\hline NPC (Gd- at baseline) & 56 & 37 & 11 & 3 & 5 & & \\
\hline PC (Gd+ at baseline) & 8 & 5 & 1 & 1 & 2 & $0.43(0.10-1.79) ; p=0.25$ & $0.10(0.01-2.13) ; p=0.14$ \\
\hline NPC (Gd+ at baseline) & 57 & 20 & 14 & 8 & 15 & & \\
\hline \multicolumn{8}{|l|}{ New T2 lesions } \\
\hline PC (all) & 122 & $66(57.3)$ & $19(13.1)$ & $14(10.6)$ & $23(18.8)$ & $0.37(0.21-0.62) ; p<0.001$ & $0.65(0.30-1.41) ; p=0.27$ \\
\hline NPC (all) & 113 & $34(30)$ & $14(12.3)$ & $11(9.7)$ & $54(47.7)$ & & \\
\hline PC (Gd- at baseline) & 104 & 58 & 18 & 11 & 17 & $0.55(0.29-1.07) ; p=0.077$ & $0.97(0.39-2.38) ; p=0.95$ \\
\hline NPC (Gd- at baseline) & 56 & 23 & 8 & 3 & 22 & & \\
\hline PC (Gd+ at baseline) & 9 & 4 & 1 & 1 & 3 & $0.30(0.07-1.30) ; p=0.11$ & $0.26(0.02-3.48) ; p=0.31$ \\
\hline NPC (Gd+ at baseline) & 57 & 11 & 6 & 8 & 32 & & \\
\hline
\end{tabular}

Abbreviations: Gd = gadolinium-enhancement status; $\mathrm{N}=$ number of subjects available for analysis; NPC = no pregnancies cohort; $\mathrm{PC}=$ pregnancies cohort. The adjusted OR is from a logistic regression model controlling for disease duration (all models) and time between scans (all time point 2 models), with $95 \%$ Cls shown as well.

DMT prepartum and postpartum treatment information was available for 120 subjects (table 2). We assessed whether DMT use preconception was associated with inflammatory activity on postpartum MRI and found no association (treated $\mathrm{n}=84(70.0 \%)$, untreated $\mathrm{n}=36(30.0 \%)$, and the presence of either postpartum new Gd+ lesions $(p=0.73)$ or new T2 lesions $(p=0.94)$. Given the recent reports of increased rebound MS activity peripartum after certain DMTs discontinuation, 8,9 we further categorized DMTs as selfinjectable $(n=62)$ vs oral and infusion $(n=20)$ and found no association between prepartum DMT category and postpartum new $\mathrm{Gd}+$ lesion $(p=0.32)$ or new T2 lesion ( $p=$ $0.61)$. The number of participants in the oral and infusion groups was too small to further stratify and analyze by specific DMT (fingolimod + natalizumab vs others). Similarly, there was no association between postpartum DMT use and MRI changes.

76 of 121 subjects (62.8\%) had postpartum MRI assessment before restarting DMTs, and the others received various DMTs concurrent with postpartum imaging. There was no correlation between DMT type or status and postpartum Gd+ $(p=0.84)$ or new T2 $(p=0.56)$ MRI activity.

In addition, we evaluated whether prophylactic steroid use (1 g IV methylprednisolone monthly) postpartum $(\mathrm{n}=19)$ was associated with MRI activity. Steroid exposure was only recorded if they were administered as monthly treatments in lieu of conventional DMT therapy. They were commenced after delivery and discontinued at the time of DMT initiation. There was no association between steroid use and postpartum new $\mathrm{Gd}+(p=0.21)$ or new T2 $(p=0.57)$ lesions.

Finally, breastfeeding information (assumed nonexclusive) was available for 120 patients. Eighty-five (71\%) breastfed for any length of time; 42 (49\%) of those breastfed for 6 months or more. Thirty-five (41\%) breastfed for 3 months or less, and 8 (9\%) breastfed between 3 and 6 months. We found no association between breastfeeding status and MRI activity in our sample. Specifically, there was no difference between a duration of breastfeeding greater or less than 3 months and new T2 $(p=0.66)$ or $\mathrm{Gd}+(p=0.84)$ lesions. We also found 
no difference between breastfeeding for 6 months or longer vs fewer than 6 months and new T2 $(p=0.43)$ or new Gd+ $(p=$ 0.17 ) lesions. In addition, baseline (prepartum) MRI status was not associated with subsequent breastfeeding choices; specifically, there was no association between the prepartum presence of Gd+ MRI lesions and ever breastfeeding ( $p=$ $0.85)$, breastfeeding for 3 or more months vs less or none ( $p=$ 34 ), or breastfeeding for 6 or more months vs less or none $(p=43)$.

\section{Cohort 2: NPC and comparison with PC}

From the phase III pivotal trials described above, 126 participants were selected to serve as a nonpregnant untreated control group (table 1). They were matched for sex, age, and EDSS to assure inclusion of reproductive age females. The cohorts were different by disease duration and MRI interval. NPC had a shorter disease duration and a longer MRI interval. The 2 cohorts were also different in the baseline level of inflammatory MRI activity, with more patients in the NPC cohort exhibiting $\mathrm{Gd}+$ lesions compared with subjects with PC $(p<0.01)$ (table 3, figure).

As shown in table 3 , and the figure, comparing the 2 cohorts in the on-study level of MRI activity, the NPC was significantly more active at the follow-up on both on $\mathrm{Gd}+$ and new $\mathrm{T} 2$ lesions in unadjusted analysis. For example, $57 \%$ of those in PC vs $30 \%$ in NPC had no new T2 lesions at follow-up. However, in analyses adjusted for disease duration and MRI interval, these differences became nonsignificant. Given the baseline difference in $\mathrm{Gd}+$ status between groups, we compared the groups in 3 ways as shown in table 3: (1) all subjects, (2) Gd+ at baseline, and (3) Gd- at baseline. In the subgroup Gd- at baseline, $32 \%$ of the PC and $\sim 34 \%$ of the NPC had $\mathrm{Gd}+$ activity on follow-up MRI. The estimated OR for the comparison of the 2 groups was OR 0.92 (95\% CI 0.46-1.83; $p=0.81)$. After adjusting for disease duration and time between scans, the adjusted OR was 1.00 (95\% CI 0.40-2.49; $p=0.99)$. Similarly, in comparing the PC and NPC groups, considering all participants regardless of baseline $\mathrm{Gd}$ status, there was no difference in $\mathrm{Gd}+$ or new T2 lesions at follow-up when adjusting for disease duration and time between scans.

\section{Discussion}

Previous smaller studies suggested an increase in postpartum MRI activity in patients with MS and a higher rate of conversion from RIS to clinically isolated syndrome (CIS) after pregnancy. ${ }^{7,12}$

We report the first large observational study of MRI-defined disease activity in patients with MS postpartum, with comparison to an age-matched nonpregnant female cohort of reproductive potential from placebo arms of 2 clinical trials. We assessed postpartum relapses and MRI activity (new Gd+ or new T2 lesions) compared with baseline prepregnancy MRI. Considering the abundant literature addressing clinical relapses peripartum, ${ }^{6,23,24}$ this was not specifically analyzed in our study. Our findings of postpartum clinical disease activity agree with those studies. However, we also found a high level of MRI disease activity. We focused on new Gd+ lesions because of their known transience. ${ }^{25}$ Over $50 \%$ of participants had active disease, as defined by either clinical relapses or new $\mathrm{T} 2$ or Gd+ lesions and $25 \%$ had both new clinical and radiographic activity postpartum. In addition, this study suggests a significant association $(p<0.001)$ between postpartum clinical and MRI changes. Interestingly, most (63\%) active postpartum MRI scans were from participants with inactive disease prepregnancy. Furthermore, $15 \%$ of clinically stable patients, with no postpartum relapses, had a new $\mathrm{Gd}+$ lesion. Peripartum EDSS scores showed no relationship with MRI activity postpartum. These observations underscore the importance of MRI surveillance in the postpartum period, regardless of clinical status.

A report from Kaiser Permanente suggested a lower prepartum and postpartum clinical disease activity than our study. ${ }^{26}$ Thirty-eight percent of Kaiser subjects were untreated before pregnancy, making effects of high-efficacy therapies on outcomes less likely. Nearly $15 \%$ of participants in the Kaiser study had CIS, and many patients were diagnosed with clinically definite MS based on a single relapse and MRI changes, rather than recurrent relapses. The Kaiser community-based, neurologically "healthier" catchment would seem to have overall milder disease compared with more complex, tertiary referrals to university-based academic centers such as ours. The Kaiserintegrated care delivery system may also differ in resources and treatment protocols from a more common fee-forservice model. These differences may make direct comparisons of outcomes across studies more challenging to interpret. $^{27}$

A high number of participants with postpartum active MRI and breakthrough on NEDA status in our study was unexpected. Although clinical predictors of postpartum relapses have been suggested, ${ }^{24,28,29}$ there is no information on whether these predictors would link to MRI-defined postpartum inflammation. Many pregnancy-specific immunologic factors have been implicated in both disease stabilization intrapartum and a higher probability of disease worsening postpartum. During pregnancy, there is an increase in antiinflammatory $\mathrm{T}$ helper 2 (Th2) immune responses and a decrease in Th1 and Th17 immune responses and their corresponding cytokines ${ }^{30,31}$ such as IFN- $\gamma$, tumor necrosis factor- $\alpha$, interleukin (IL)-17, and regulatory cytokines (IL-10). This shift promotes protolerogenic state between the mother and genetically foreign fetal-placental unit. ${ }^{32}$ It may also provide an immunologic benefit for pregnant patients with MS, which is rapidly lost on delivery, resulting in an increased probability of an inflammatory response in the postpartum state.

Estradiol, estriol, and progesterone increase gradually during pregnancy and peak in the third trimester. Both in vivo and in 
vitro observations have demonstrated that estriol, the estrogen made by the fetal placenta, may support the shift from Th1 to Th2. ${ }^{33}$ Patients with MS treated with exogenous estriol are reported to have decreased numbers of $\mathrm{Gd}+$ lesions during treatment, but their MRI activity returned to baseline within 3 months after discontinuation of estriol. ${ }^{33}$ Abrupt declines in estriol levels immediately on delivery may mimic the observations made in early phase clinical trials and similarly manifest as increased inflammatory activity postpartum. $\mathrm{Gd}+$ activity is a more sensitive marker of CNS inflammation than relapses alone. ${ }^{34}$ It has been used as a primary outcome measure in early phase clinical trials. ${ }^{35}$ Therefore, it is reasonable to expect that in a cohort showing postpartum disease activity, inflammatory MRI changes will be more frequent than clinical activity alone.

There are several limitations to this study. In PC, we only included full-term pregnancies that resulted in a live birth. This could introduce a sampling bias toward a healthier cohort because some of the reasons for stopping or losing a pregnancy (terminations or miscarriages) may have included worsening neurologic disease. However, the finding of increased inflammatory activity in our sample is not predicted, based on this possible bias.

We did not find any significant correlation between DMT use peripartum and on-study MRI changes. However, only a few of our participants received high-efficacy treatments before pregnancy and our sample was not sufficiently powered to perform a comparative analysis of DMT subtypes (e.g., oral vs infusion medications). All participants discontinued DMTs within historically appropriate FDA-recommended guidelines, thus making a direct impact of DMTs on disease activity in the postpartum period less likely. However, we do not have the exact timing of DMT discontinuation before pregnancy, and this is a limitation of our data set. Exposures to any DMT within 1-2 years before pregnancy is associated with a lower risk of postpartum relapse. ${ }^{24}$ We did not observe this relationship with postpartum relapses or inflammatory MRI activity.

We were not able to ascertain exclusive vs nonexclusive breastfeeding status in our cohort. Furthermore, because of the lack of precise information on the timing of breastfeeding and DMT usage in the postpartum period, we felt that the data were not suitable to perform a multivariate analysis assessing the contribution of these 2 factors to postpartum MRI activity.

Several studies have suggested that breastfeeding may influence postpartum relapse rate. Exclusive breastfeeding in MS is protective against postpartum relapses. ${ }^{36}$ Nonexclusive breastfeeding studies failed to reproduce these findings. ${ }^{37} \mathrm{~A}$ recent systematic review and meta-analysis reported a $43 \%$ reduction in the postpartum MS relapse rate in women who breastfed exclusively. ${ }^{38}$ Therefore, exclusive breastfeeding status ascertainment is important.
Finally, we must consider extended time off DMT as a possible explanation for high postpartum inflammatory MS activity. The time off DMTs is inherent to the state of pregnancy, especially with DMT labeling instructions and DMT pregnancy exposure warnings concurrent with our study time frame.

In an effort to separate the effect of pregnancy from the long-term untreated state, we obtained a control group of reproductive age untreated women with MS. Although selecting this cohort from our Center might have allowed better baseline matching, there would likely be a bias toward "benign MS" in women opting for no DMTs. Thus, it is important to recognize that, although our 2 comparator cohorts were well matched by age and EDSS, they had different characteristics, i.e., disease duration and MRI interval. NPC had more active radiographic disease at baseline. The PC, on the contrary, had mostly stable disease prepregnancy, as expected and advised for patients starting a family. We adjusted for these baseline factors in our analysis, which changed the results: the onstudy differences between the 2 cohorts in the number of $\mathrm{Gd}+$ and new T2 lesions became nonsignificant. This may suggest that pregnancy and the postpartum period collectively resembles an untreated MS observation sample in its MRI activity.

However, despite very few patients with prepartum Gd+ MRI activity in PC, we observed a remarkable increase in the number of patients with new MRI-defined inflammation postpartum. Subjects from NPC, although more active at baseline, did not substantially change their level of MRI activity over 2 years. This underscores the possible effect of the pregnancy to the postpartum period on the increase in inflammatory activity. Although this observation warrants further investigation, we cannot positively conclude whether an increase in postpartum MRI disease activity in PC is related to pregnancy, the postpartum state, or the extended time off DMT because of the baseline differences between the 2 groups.

Another important limitation of our analysis is that we do not know if new T2 lesions occurred during pregnancy or postpartum. In addition, in the pregnancy cohort, the risk of new lesion formation between the prepartum MRI and the postpartum MRI is not uniformly distributed, whereas it should be uniformly distributed during the placebo arm of a clinical trial. This is a major limitation of comparing the 2 cohorts.

Previous studies suggest no correlation between postpartum relapse rates and long-term increases in MS disability. ${ }^{28,35,39,40}$ It is not known whether an increase in postpartum MRI activity, in addition to an increase in clinical activity, or as a separate metric, may be associated with long-term disability changes. Further studies are needed for clarification.

This is the first large observational study investigating MRIdefined disease activity in the postpartum period. Our findings demonstrate higher levels of disease activity, by both clinical and neuroimaging measures, than previously reported, suggesting that postpartum period may remain a vulnerable 
time. MRI provides a sensitive tool to assess disease activity postpartum. Further research is needed to evaluate how MRI and clinical activity is influenced by early vs delayed resumption of treatment and how the effects of breastfeeding modulate such activity.

\section{Study funding}

Sanofi Genzyme provided funding through an unrestricted investigator-initiated research study (M. Houtchens).

\section{Disclosure}

M. Houtchens has received consulting and advisory board fees from Biogen, EMD-Serono, Genzyme-Sanofi, Novartis, and Roche-Genentech; she has received research support from Genzyme-Sanofi, Biogen, and Merck. R. Bove has received consulting and advisory board fees from Alexion, Biogen, EMD-Serono, Genzyme-Sanofi, Novartis, Pear Therapeutics, and Roche-Genentech; she has received research support from Akili Therapeutics. B. Healy received research support from Analysis Group, Verily Life Sciences, Novartis, Merck Serono, and Genzyme. S. Houtchens reports no disclosures. T.B. Kaplan has received consulting and advisory board fees from Alexion, Biogen, Genzyme-Sanofi, and Celgene. T. Chitnis has received research funding from Serono, Mallinckrodt, Novartis, and Verily and has participated as a consultant or advisor for Biogen, Novartis, Sanofi-Genzyme. R. Bakshi has received consulting fees from Bayer, Biogen, Celgene, EMD Serono, Genentech, and Novartis, and research support from EMD Serono and Sanofi-Genzyme. The authors have no conflicts of interest relevant to this article to disclose. Go to Neurology. org/NN for full disclosures.

\section{Publication history}

Received by Neurology: Neuroimmunology \& Neuroinflammation March 30, 2020. Accepted in final form August 19, 2020.

\section{Appendix Authors}

\begin{tabular}{lll}
\hline Name & Location & Contribution \\
\hline $\begin{array}{l}\text { Maria } \\
\text { Houtchens, }\end{array}$ & $\begin{array}{l}\text { Brigham and Women's } \\
\text { Mospital, BSc }\end{array}$ & $\begin{array}{l}\text { Conceptualized and designed } \\
\text { the study, major role with data } \\
\text { acquisition, and drafted and } \\
\text { revised manuscript for } \\
\text { intellectual content }\end{array}$
\end{tabular}

\begin{tabular}{lll}
\hline $\begin{array}{l}\text { Riley Bove, } \\
\text { MD, MSc }\end{array}$ & Saniversity of California, & $\begin{array}{l}\text { Assisted with the study design, } \\
\text { data analysis, and drafting and } \\
\text { revising the manuscript for } \\
\text { intellectual content }\end{array}$
\end{tabular}

\begin{tabular}{lll}
\hline $\begin{array}{l}\text { Brian } \\
\text { Healy, PhD }\end{array}$ & $\begin{array}{l}\text { Brigham and Women's } \\
\text { Hospital, Boston, MA }\end{array}$ & $\begin{array}{l}\text { Performed data analysis and } \\
\text { manuscript revisions for } \\
\text { intellectual content }\end{array}$ \\
\hline $\begin{array}{l}\text { Stepan } \\
\text { Houtchens, } \\
\text { BS }\end{array}$ & $\begin{array}{l}\text { National Forensic } \\
\text { Cybersecurity Alliance, } \\
\text { Pittsburgh, PA }\end{array}$ & $\begin{array}{l}\text { Major role in data collection } \\
\text { and analysis and assisted with } \\
\text { revising the manuscript for } \\
\text { intellectual content }\end{array}$ \\
\hline $\begin{array}{l}\text { Tamara } \\
\text { Bockow } \\
\text { Kaplan, MD }\end{array}$ & $\begin{array}{l}\text { Brigham and Women's } \\
\text { Hospital, Boston, MA }\end{array}$ & $\begin{array}{l}\text { Major role in data collection } \\
\text { and assisted with drafting the } \\
\text { manuscript }\end{array}$ \\
\hline
\end{tabular}

Appendix (continued)

\begin{tabular}{lll}
\hline Name & Location & Contribution \\
\hline $\begin{array}{l}\text { Tatenda } \\
\text { Mahlanza, } \\
\text { MSc }\end{array}$ & $\begin{array}{l}\text { Brigham and Women's } \\
\text { Hospital, Boston, MA }\end{array}$ & $\begin{array}{l}\text { Major role in data collection } \\
\text { and assisted with revising the } \\
\text { manuscript for intellectual } \\
\text { content }\end{array}$ \\
\hline $\begin{array}{l}\text { Tanuja } \\
\text { Chitnis, MD }\end{array}$ & $\begin{array}{l}\text { Brigham and Women's } \\
\text { Hospital, Boston, MA }\end{array}$ & $\begin{array}{l}\text { Assisted with study design and } \\
\text { revised the manuscript for } \\
\text { intellectual content }\end{array}$ \\
\hline $\begin{array}{l}\text { Rohit } \\
\text { Bakshi, MD }\end{array}$ & $\begin{array}{l}\text { Brigham and Women's } \\
\text { Hospital, Boston, MA }\end{array}$ & $\begin{array}{l}\text { Assisted with study design, data } \\
\text { analysis, and drafting and } \\
\text { revising the manuscript for } \\
\text { intellectual content }\end{array}$ \\
\hline
\end{tabular}

\section{References}

1. Wallin MT, Culpepper WJ, Campbell JD, et al. The prevalence of MS in the United States: a population-based estimate using health claims data. Neurology 2019;92: e1029-e1040.

2. Alonso A, Hernan MA. Temporal trends in the incidence of multiple sclerosis: a systematic review. Neurology 2008;71:129-135.

3. Ysrraelit MC, Correale J. Impact of sex hormones on immune function and multiple sclerosis development. Immunology 2019;156:9-22.

4. Miller DH, Fazekas F, Montalban X, Reingold SC, Trojano M. Pregnancy, sex and hormonal factors in multiple sclerosis. Mult Scler 2014;20:527-536.

5. Houtchens MK, Edwards NC, Schneider G, Stern K, Phillips AL. Pregnancy rates and outcomes in women with and without MS in the United States. Neurology 2018;91: e1559-e1569.

6. Confavreux C, Hutchinson M, Hours MM, Cortinovis-Tourniaire P, Moreau T. Rate of pregnancy-related relapse in multiple sclerosis. Pregnancy in Multiple Sclerosis Group. N Engl J Med 1998;339:285-291.

7. Lebrun C, Le Page E, Kantarci O, et al. Impact of pregnancy on conversion to clinically isolated syndrome in a radiologically isolated syndrome cohort. Mult Scler 2012;18:1297-1302

8. Geissbuhler Y, Vile J, Koren G, et al. Evaluation of pregnancy outcomes in patients with multiple sclerosis after fingolimod exposure. Ther Adv Neurol Disord 2018;11: 1756286418804760 .

9. Alroughani R, Alowayesh MS, Ahmed SF, Behbehani R, Al-Hashel J. Relapse occurrence in women with multiple sclerosis during pregnancy in the new treatment era. Neurology 2018;90:e840-e846.

10. Shobeiri E, Torabinejad B. Brain magnetic resonance imaging findings in postpartum headache. Neuroradiol J 2019;32:4-9.

11. Zak IT, Dulai HS, Kish KK. Imaging of neurologic disorders associated with pregnancy and the postpartum period. Radiographics 2007;27:95-108.

12. Paavilainen T, Kurki T, Parkkola R, et al. Magnetic resonance imaging of the brain used to detect early post-partum activation of multiple sclerosis. Eur J Neurol 2007; 14:1216-1221.

13. Hellwig K, Correale J. Artificial reproductive techniques in multiple sclerosis. Clin Immunol 2013;149:219-224.

14. Polman CH, Reingold SC, Edan G, et al. Diagnostic criteria for multiple sclerosis: 2005 revisions to the "McDonald Criteria". Ann Neurol 2005;58:840-846.

15. Comi G, Jeffery D, Kappos L, et al. Placebo-controlled trial of oral laquinimod for multiple sclerosis. N Engl J Med 2012;366:1000-1009.

16. Vollmer TL, Sorensen PS, Selmaj K, et al. A randomized placebo-controlled phase III trial of oral laquinimod for multiple sclerosis. J Neurol 2014;261:773-783.

17. Kurtzke JF. Rating neurologic impairment in multiple sclerosis: an expanded disability status scale (EDSS). Neurology 1983;33:1444-1452.

18. Kalincik T. Multiple sclerosis relapses: epidemiology, outcomes and management. A systematic review. Neuroepidemiology 2015;44:199-214.

19. Filippi M, Rocca MA, Pagani E, et al. Placebo-controlled trial of oral laquinimod in multiple sclerosis: MRI evidence of an effect on brain tissue damage. J Neurol Neurosurg Psychiatry 2014;85:851-858.

20. Bevan CJ, Cree BA. Disease activity free status: a new end point for a new era in multiple sclerosis clinical research? JAMA Neurol 2014;71:269-270.

21. Havrdova E, Giovannoni G, Stefoski D, et al. Disease-activity-free status in patients with relapsing-remitting multiple sclerosis treated with daclizumab high-yield process in the SELECT study. Mult Scler 2014;20:464-470.

22. Lu G, Beadnall HN, Barton J, Hardy TA, Wang C, Barnett MH. The evolution of "No Evidence of Disease Activity" in multiple sclerosis. Mult Scler Relat Disord 2018;20: 231-238.

23. Houtchens MK, Edwards NC, Phillips AL. Relapses and disease-modifying drug treatment in pregnancy and live birth in US women with MS. Neurology 2018;91: e1570-e1578.

24. Hughes SE, Spelman T, Gray OM, et al. Predictors and dynamics of postpartum relapses in women with multiple sclerosis. Mult Scler 2014;20:739-746. 
25. Absinta M, Sati P, Reich DS. Advanced MRI and staging of multiple sclerosis lesions. Nat Rev Neurol 2016;12:358-368.

26. Langer-Gould A, Smith J, Albers K, et al. Pregnancy-related relapses in a large, contemporary multiple sclerosis cohort: no increased risk in the postpartum period (S6.007). Neurology 2019;92(suppl 15):S6.007.

27. Maeda JL, Lee KM, Horberg M. Comparative health systems research among Kaiser Permanente and other integrated delivery systems: a systematic literature review. Perm J 2014;18:66-77.

28. Vukusic S, Hutchinson M, Hours $M$, et al. Pregnancy and multiple sclerosis (the PRIMS study): clinical predictors of post-partum relapse. Brain 2004;127:1353-1360.

29. Hellwig K, Rockhoff M, Herbstritt S, et al. Exclusive breastfeeding and the effect on postpartum multiple sclerosis relapses. JAMA Neurol 2015;72:1132-1138.

30. Ander SE, Diamond MS, Coyne CB. Immune responses at the maternal-fetal interface. Sci Immunol 2019; 4:eaat6114.

31. Buyon JP. The effects of pregnancy on autoimmune diseases. J Leukoc Biol 1998;63:281-287.

32. Ghaebi M, Nouri M, Ghasemzadeh A, et al. Immune regulatory network in successful pregnancy and reproductive failures. Biomed Pharmacother 2017;88:61-73.

33. Sicotte NL, Liva SM, Klutch R, et al. Treatment of multiple sclerosis with the pregnancy hormone estriol. Ann Neurol 2002;52:421-428.
34. Kaunzner UW, Gauthier SA. MRI in the assessment and monitoring of multiple sclerosis: an update on best practice. Ther Adv Neurol Disord 2017;10: 247-261.

35. Verdru P, Theys P, D'Hooghe MB, Carton H. Pregnancy and multiple sclerosis: the influence on long term disability. Clin Neurol Neurosurg 1994;96:38-41.

36. Langer-Gould A, Huang SM, Gupta R, et al. Exclusive breastfeeding and the risk of postpartum relapses in women with multiple sclerosis. Arch Neurol 2009;66: 958-963.

37. Portaccio E, Ghezzi A, Hakiki B, et al. Breastfeeding is not related to postpartum relapses in multiple sclerosis. Neurology 2011;77:145-150.

38. Krysko KM, Rutatangwa A, Graves J, Lazar A, Waubant E. Association between breastfeeding and postpartum multiple sclerosis relapses: a systematic review and meta-analysis. JAMA Neurol 2019;77:327-338.

39. Masera S, Cavalla P, Prosperini L, et al. Parity is associated with a longer time to reach irreversible disability milestones in women with multiple sclerosis. Mult Scler 2015; 21:1291-1297.

40. Weinshenker BG, Hader W, Carriere W, Baskerville J, Ebers GC. The influence of pregnancy on disability from multiple sclerosis: a population-based study in Middlesex County, Ontario. Neurology 1989;39:1438-1440. 


\section{Neurology \\ Neuroimmunology \& Neuroinflammation}

\section{MRI activity in MS and completed pregnancy: Data from a tertiary academic center Maria Houtchens, Riley Bove, Brian Healy, et al. Neurol Neuroimmunol Neuroinflamm 2020;7; \\ DOI 10.1212/NXI.0000000000000890}

This information is current as of September 11, 2020

Updated Information \& Services

References

Subspecialty Collections

Permissions \& Licensing

Reprints including high resolution figures, can be found at: http://nn.neurology.org/content/7/6/e890.full.html

This article cites 40 articles, 2 of which you can access for free at: http://nn.neurology.org/content/7/6/e890.full.html\#\#ref-list-1

This article, along with others on similar topics, appears in the following collection(s):

MRI

http://nn.neurology.org//cgi/collection/mri

Multiple sclerosis

http://nn.neurology.org//cgi/collection/multiple_sclerosis

Information about reproducing this article in parts (figures,tables) or in its entirety can be found online at:

http://nn.neurology.org/misc/about.xhtml\#permissions

Information about ordering reprints can be found online: http://nn.neurology.org/misc/addir.xhtml\#reprintsus

Neurol Neuroimmunol Neuroinflamm is an official journal of the American Academy of Neurology.

Published since April 2014, it is an open-access, online-only, continuous publication journal. Copyright

Copyright (C) 2020 The Author(s). Published by Wolters Kluwer Health, Inc. on behalf of the American Academy of Neurology.. All rights reserved. Online ISSN: 2332-7812.

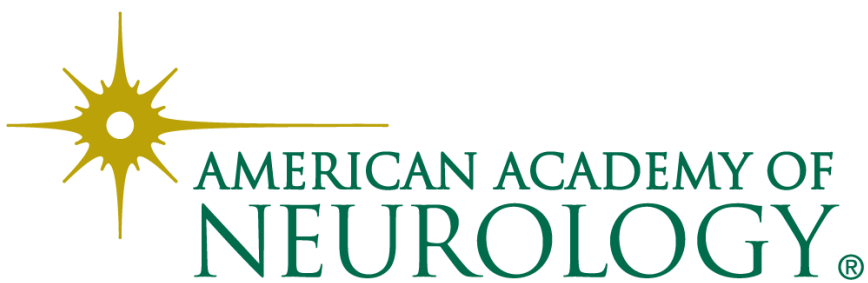

